\title{
Foster and kinship carer survey: accessing health services for children in out-of-home care
}

Type of manuscript: Original article

Karen McLean ${ }^{1,2,3}$, Harriet Hiscock ${ }^{2,3,4,5}$, Dorothy Scott ${ }^{6}$, Sharon Goldfeld ${ }^{1,2,3}$

\section{Addresses of institutions}

1. Policy and Equity, Murdoch Children’s Research Institute, Parkville, Victoria, Australia;

2. Centre for Community Child Health, Royal Children’s Hospital, Parkville, Victoria, Australia;

3. Department of Paediatrics, University of Melbourne, Parkville, Victoria, Australia.

4. Health Services, Murdoch Children’s Research Institute, Parkville, Victoria, Australia

5. Health Services Research Unit, Royal Children’s Hospital, Parkville, Victoria, Australia

6. Department of Social Work, Health Sciences, University of Melbourne

\section{Full postal, email addresses and phone number of corresponding author}

Corresponding author:

Dr Karen McLean

Address: Centre for Community Child Health, Level 2 East, Royal Children’s Hospital, 50 Flemington Road, Parkville, VIC 3052, Australia.

Email: karen.mclean@rch.org.au

Phone: +61 393456504

\section{Acknowledgements}

This is the author manuscript accepted for publication and has undergone full peer review but has not been through the copyediting, typesetting, pagination and proofreading process, which may lead to differences between this version and the Version of Record. Please cite this article as doi: 10.1111/jpc.15157

This article is protected by copyright. All rights reserved. 
KMcL led the research project and the writing of the paper. All authors contributed to planning the analysis, writing the paper and reviewing drafts.

Thanks to the Foster Care Association of Victoria for co-design and pilot-testing of the survey and for distributing the survey to members; thanks to Kinship Carers Victoria for distributing the survey to their members, and to the foster care agencies who encouraged carers to complete the survey.

This research is supported the Victorian Government's Operational Infrastructure Support Program. KM is supported by an Australian Government Research Training Program Scholarship PhD scholarship and Murdoch Children’s Research Institute scholarship. SG is supported by Australian National Health and Medical Research Council (NHMRC) Career Development Fellowship 1082922. HH is supported by Australian National Health and Medical Research Council (NHMRC) Career Development Fellowship 1136222.

No author has a conflict of interest.

\section{Abstract}

\section{Aim:}

To explore the experiences of Victorian foster and kinship carers in accessing health services for children in their care and to quantify the frequency of potential barriers to healthcare.

\section{Methods:}

On-line survey, co-designed with the Foster Care Association of Victoria measuring carerreported health service engagement by a child/young person in their care; ease of service access; time to receiving Medicare number and out-of-pocket health-related costs. 239 foster and 51 kinship carers were recruited through email and social media by carer support agencies.

\section{Results:}


$90 \%$ of children/young people had engaged with a general practitioner. Most had engaged with dental (75\%), paediatric (72\%), optometry (61\%) and audiology (54\%) services. Mental health services were most likely to be needed but not yet received. Neither carer education nor socio-economic status was associated with likelihood of service engagement. Carers reported that it was hardest to get appointments with mental health and paediatric services. $27 \%$ had waited to see a health service because of delays in carers receiving their Medicare number. $60 \%$ of carers had paid out-of-pocket for health services; $78 \%$ of these had not been reimbursed.

\section{Conclusions}

Victorian foster and kinship carers report high health service use for children and young people in their care. Mental health services were the hardest to access with the largest gap between identified need and service use. Timely access to Medicare numbers and financial support are barriers to access that could be addressed. The development of integrated paediatric healthcare and clinicians co-located with Child Protection could also assist. 


\section{What is already known:}

Children and young people in out-of-home care have higher health needs than the general population.

There are barriers to the provision of appropriate health care to children and young people in out-of-home care.

Carers play a key role in facilitating health care for these children and young people.

\section{What this paper adds:}

This is the first Australian study exploring carer experiences accessing healthcare.

Mental health services were the hardest for carers to access, with the largest gap between need and service engagement.

Specific barriers to accessing health care (Medicare numbers and out-of-pocket costs) have been quantified for the first time.

\section{Key words}

Foster home care

Surveys and questionnaires

Health services accessibility

Health services needs and demand 


\section{Introduction}

On any given day in Victoria, around 8,500 children and young people (aged 0 - 17 years) are living in a statutory out-of-home care (OOHC) placement, court ordered due to substantiated reports of abuse and/or neglect. The vast majority (94\%) are in home-based placements, with either a kinship (member of the extended family or network) (73\%) or foster carer (19\%). More children enter and exit OOHC in Victoria, with a shorter median duration in OOHC, than any other Australian state or territory. ${ }^{1}$

Studies within Australia and internationally have demonstrated that these children and young people have higher prevalence of health needs across all domains of health: physical, developmental and mental health. ${ }^{2-4}$ Due to these high rates of need, Australian and international peak health bodies and state and federal guidelines recommend routine assessment of health needs upon entry to out-of-home care (including dental, hearing and vision assessments), followed by the appropriate services or treatments as required. ${ }^{5-7}$ However, in Victoria there is no state-wide pathway for the delivery of such assessments, no state-wide consistency in access to paediatricians and no monitoring of compliance with recommendations.

Access to health services for children and young people in OOHC is often complex. Barriers include insufficient availability of services, ${ }^{8,9}$ lack of clarity around roles, responsibilities and authorisation of the adults and agencies involved, ${ }^{10}$ bureaucratic delays and the challenges of navigating a complicated health system. ${ }^{10,11}$ The foster or kinship carer plays an important role in facilitating health-care but also faces the logistic difficulties inherent in attending appointments including time, parking, child-care for other children in their care and out-ofpocket costs. $^{8,11,12}$

There are several studies that explore the experience of kinship and foster carers in accessing health services for children in their care, some of which focus specifically on access to mental health services. Internationalstudies have identified challenges with inadequate service provision across paediatric and mental health services, long waiting lists and out-of-pocket costs to carers. ${ }^{8,9}$ 
We have only identified a handful of papers exploring the experiences of carers in Australia. Octoman and McLean (2014) surveyed carers (predominantly in South Australia, New South Wales and Queensland) and found they wanted better access to General Practitioners and mental health services to respond to mental health and behavioural needs. ${ }^{13}$ Sawyer et al. (2007) also found the carers reported difficulty accessing mental health services in a timely way, with only half of young people identified as needing help receiving it in the previous six months. ${ }^{14}$ A qualitative study of carers in Queensland found they reported difficulties accessing resources, including counselling. ${ }^{15}$ To our knowledge, there have been no studies either quantifying or exploring carer experiences within Victoria. Since child protection services and many health services are delivered by state governments within Australia, it is important to understand the issues in each different system.

We therefore aimed to identify some experiences of Victorian foster and kinship carers in accessing health services for children in their care and to quantify the frequency of two potential barriers to healthcare.

\section{Methods}

Survey design

We co-designed an on-line survey with the Foster Care Association of Victoria (FCAV) to ask carers about their experiences. The topics for inclusion in the survey arose from the Foster Carer Handbook Victoria ${ }^{16}$ and previous literature review (see Table 1). The wording of both questions and answers was refined based on feedback from pilot participants.

\section{Participants}

The target population was foster and kinship carers in Victoria, who had cared for a child or young person on statutory child protection orders within the last five years, with only one survey to be completed per household.

Recruitment occurred through peak carer bodies and foster and kinship care agencies. The public survey link was distributed via email, hard copy newsletter and through social media channels by the FCAV. The link was also promoted by Kinship Carers Victoria and some 
Victorian community service organisations who support foster and/or kinship carers, with reminders during the 10 weeks that the survey was open (September - December 2018).

\section{Data collection and analysis}

Study data were collected and managed using REDCap, (Research Electronic Data Capture), a secure, web-based data capture application hosted at MCRI. ${ }^{17}$

Analysis was completed using Stata version 15.1, including simple descriptive statistics and binomial regression analysis to explore whether (i) engagement with health services, (ii) ease of making appointments (iii) timely receipt of Medicare numbers or (iv) likelihood of out-ofpocket costs was associated with carer or child factors, including age of child, number of previous placements, location, carer education level or carer socio-economic status (as defined by the Socio-Economic Indexes for Areas (SEIFA) by postcode).

This project had ethics approval from the local Human Research Ethics Committee (38163A).

\section{Results}

353 records were created in REDCap, with 290 included for analysis after excluding participants who: provided no answers beyond the consent page (29); provided a postcode not within $20 \mathrm{~km}$ of the Victorian state border (11); were caring for a child not on statutory orders (3); provided no health service use data (17); were identified as duplicates (3).

The response rate was estimated due to the distribution method. As of 30 June 2018, children/young people were placed in 5,567 Victorian carer households, including 998 foster households and 3,705 kinship households although other sources suggest that there were around 1800 active foster carer households in 2018. ${ }^{1,18}$ Our survey therefore was completed by $5.2 \%$ of all Victorian carer households, and the 239 foster carers comprise 13 - 24\% of foster carer households.

Kinship carers were under-represented in the study. Other variables, including age and experience as a carer, were broadly consistent with the population of Victorian foster carers 
(Table 2). ${ }^{18,19}$ Carers completing the survey were from across the state with 170 unique postcodes and all 17 Department of Health and Human Services (DHHS) areas represented amongst the 271 carers who provided their postcode. $41 \%$ did not live in metropolitan Melbourne. Carers were supported by 24 different foster carer agencies. The children/young people placed with the carers were broadly representative of the wide population living in OOHC. ${ }^{1}$

Carer responses for health service use were collapsed to define engagement with a service as having attended, having an appointment or being on a waiting list with a health service (the latter two categories having comparatively few responses). Carers reported over 95\% of children/young people had engaged with at least one service (Figure 1). Some carers reported they didn’t know about health service use; this varied by health service and most likely reflects the short-term nature of some placements. 89\% were known by carers to have engaged with a GP; the majority had also engaged with dental, optometry, paediatric and audiology services. Mental health services were the most likely to be needed (in the opinion of the carer) but not received (14\% of children/young people). Older children were more likely to have engaged with dental, optometry and mental health services and less likely to have engaged with a paediatrician (Table 3). Compared with children living in rural areas, children living in metropolitan areas were less likely to have engaged with a paediatrician (RR 0.84, 95\% CI 0.72-0.98), dentist (RR 0.84, 95\% CI 0.74-0.97) and optometrist (RR 0.81 95\% CI 0.60 - 0.78). Children living in kinship care were more likely to have engaged with a dentist (RR 1.25 (95\% CI 1.11-1.42) than children living in foster care. Carer education level and carer socio-economic status were not associated with likelihood of service engagement.

85\% of carers found it easy to get a GP appointment (Figure 2). Despite paediatricians being the third most frequently used health service, almost half of carers (46\%) reported that it was difficult to make an appointment. Mental health services were the most difficult to access, with $58 \%$ of carers who had tried to make an appointment with a psychologist and $66 \%$ who had tried with Child and Adolescent Mental Health Services reporting it was difficult. Kinship carers found it easier to get mental health appointments than foster carers (RR 1.8 (1.1-2.9) for psychology appointments, RR 2.6 (1.3-5.2) for CAMHS appointments. 
Location, carer education level and socio-economic status had no impact upon the ease of making appointments.

Carers were asked whether they thought the child/young person had had a good assessment of their needs across health domains (Figure 3). While most carers reported that physical needs had been well assessed, only $43 \%$ of carers thought developmental needs and 31\% mental health needs had been assessed well.

Carers were asked when they received a Medicare number or card for the child/young person in their care. While 31\% had received this within 1 month of the beginning of the placement, over $50 \%$ waited more than 3 months, including $12 \%$ who waited more than 12 months. $27 \%$ of carers reported that the child/young person had experienced delays in accessing health care due to a delay with the Medicare number. Regression analysis found that where there had been 3 or more previous placements the carer was more likely to receive the Medicare number by 3 months. There were no differences between age of child, carer socioeconomic status or metropolitan vs regional location.

$60 \%$ of carers reported paying out-of-pocket for a child/young person to receive a health service, most commonly GP appointments but across the range of services. With each increase in SEIFA quintile (representing higher socioeconomic status), the chance that carers had paid out of pocket increased by 15\% (RR: 1.15, 95\% CI $1.06-1.24$ ). Of those carers who had paid, 78\% reported that they had not been reimbursed. 


\section{Discussion}

We aimed to survey carers' experiences of accessing health services for children and young people placed in their care, and we found high levels of health service use. Compared to Australian children overall, and similar to previous studies, ${ }^{20,21}$ children and young people in OOHC have higher reported usage of GPs, paediatricians, speech therapy and mental health services. ${ }^{22}$ However, like Melbye (2014) we demonstrated less frequent dental visits for children in $\mathrm{OOHC}^{23}$. The National Child Oral Health study found that $10.3 \%$ of Victorian children aged 5-14 years had never had a dental visit, ${ }^{24}$ compared with $18 \%$ of those similarly aged ( $4-12$ years old) in this study.

These findings should be considered in the context of state and federal guidelines that recommend all children and young people who enter OOHC should have health assessments, including routine optometry, dental and audiology assessments. While use was high for many of these services, our findings suggest there may be under-utilisation of some health services compared with recommendations, given the proportion of children/young people whose carers report they have never seen a dentist or GP. It is unclear from our study whether carers are under-reporting service use because they are unaware of services that have already been received in a previous placement or whether these assessments have indeed not taken place. The gap between need and service use across all domains of health may also be underreported: Kaltner and Rissel (2011) found that a group of Australian carers under-identified health needs compared to those identified by health professionals. ${ }^{25}$

Mental health is the area of most concern for this population. Most carers thought that the mental health needs of children in their care had not been well assessed. The largest gap between carer-perceived need and service use was in mental health, and mental health services were the hardest to access. We know from previous studies that rates of mental health problems and the need for appropriate care is very high. 2, 4, 14 The limited demographic data about the children described in this study showed that $42 \%$ of those in foster care had at least three previous placements, increasing their likelihood of behavioural and mental health 
problems. ${ }^{26}$ The difficulties accessing mental health services existed across metropolitan and regional areas, regardless of carer education level or socioeconomic status. This suggests there may be systemic barriers for this population accessing mental health care that contribute to the perpetuation of the inverse care law, with those at greatest need least likely to get the care they need.

This study identified two potential barriers to health service access. Most publicly funded health services are paid for in full or in part through Medicare, which requires the child or young person's Medicare care or number. However, carers reported that it may take many months to receive the Medicare number for the child/young person in their care, and that for more than a quarter of children, this had delayed their care.

While Medicare funds many of the needed health services, some require up-front payment with later reimbursement. Others are only partly subsidised through Medicare and require additional payment, usually paid for by the carer at the time of accessing care. Foster and kinship carers do receive an allowance (between \$402 and \$1,639 fortnightly, depending on the needs of the child) which is intended to cover health along with all other costs of care, reports suggest that there is often a gap between allowances and costs, ${ }^{19}$ especially for kinship carers. ${ }^{27}$ Some out-of-pocket payments are reimbursable by Child Protection, but, over half of carers reported paying out-of-pocket for health services for children/young people placed in their care, and just over $22 \%$ of those were reimbursed.

We followed up the survey with a qualitative study of 19 carers ( 9 kinship, 9 foster and 1 both kinship \& foster) to understand the barriers and enablers in more detail. ${ }^{28}$ The follow-up study confirmed that paediatric and mental healthcare were the hardest to access and that obtaining Medicare numbers and out-of-pocket costs were barriers to healthcare. Additional barriers identified through the interviews included the complex consent and authorisation environment, a lack of publicly funded services, long waitlists at those that do exist and logistic challenges in attending appointments while still prioritising school and work.

This research with foster and kinship carers suggests that more needs to be done to facilitate both routine health assessment upon entry to care and access to trauma-informed healthcare 
services to meet identified need. Existing services could reconsider how they might prioritise children in OOHC and deliver healthcare with greater flexibility - something that the increased provision of telehealth in Australia might facilitate. The development of state-wide integrated primary care, paediatric and mental health service delivery models could also simplify pathways to care and improve access. The complexity of healthcare navigation and limitations on resources could be ameliorated by a clinical workforce sitting alongside $\mathrm{CP} / \mathrm{OOHC}$ that delivered health screening, triaging to universal services or dedicated multidisciplinary assessment teams as needed.

Strengths: This is the first Australian study to explore and quantify factors associated with better access to health care for children and young people placed in OOHC. Our carer population was representative across most demographic variables and covered the state widely. Although selection bias was a risk (those with negative experiences or with greater regard for health may have been more likely to complete the survey) the range of responses across most questions suggest that this is not a significant problem.

Limitations: While the study cohort is broadly representative, the respondents comprise only approximately 5-10\% of carer households, with kinship carers under-represented. This limits the generalisability of the findings. Health service utilisation figures are also likely to be somewhat under-reported, as they rely upon the foster carers' knowledge of past health visits, and carers did not always know. Need for health services may also be under-reported.

The closed-ended questions in the survey also limit the depth of understanding of the experiences of carers, as well as prevent gathering of additional barriers and facilitators to health service utilisation. It was for this reason that we followed the survey with qualitative research to understand the different experiences of foster and kinship carers in accessing health services, and to both explore barriers and facilitators to health service utilisation for children and young people in OOHC. Future research is needed to build an evidence base around enablers of healthcare access and timely and appropriate healthcare delivery to those in OOHC.

\section{Conclusion}


Victorian foster and kinship carers report high levels of health service use for children and young people in OOHC, although use may still not match levels of need. Most carers thought that mental health needs had not been well assessed. Mental health services were also the most difficult to access. Specific barriers that could be addressed to facilitate health service use include timely access to a Medicare number and financial support. The development of integrated paediatric healthcare and clinicians co-located with Child Protection could also assist. 


\section{References}

1. Australian Institute of Health and Welfare. Child protection Australia 2018-19. Canberra; 2020.

2. McLean K, Little K, Hiscock H, Scott D, Goldfeld S. Health needs and timeliness of assessment of Victorian children entering out-of-home care: An audit of a multidisciplinary assessment clinic. Journal of Paediatrics and Child Health. 2019; 55(12)

3. Egelund T, Lausten M. Prevalence of mental health problems among children placed in out-of-home care in Denmark. Child \& Family Social Work. 2009;14(2):156-65.

4. Tarren-Sweeney M, Hazell P. Mental health of children in foster and kinship care in New South Wales, Australia. Journal of Paediatrics \& Child Health. 2006;42(3):89-97.

5. American Academy of Pediatrics. Health Care Issues for Children and Adolescents in Foster Care and Kinship Care. Pediatrics. 2015;136(4):e1131-40.

6. Department for Education and Department of Health. Promoting the health and well-being of lookedafter children: Statutory guidance for local authorities, clinical commissioning groups and NHS England. England 2015.

7. Department of Families, Housing, Community Services and Indigenous Affairs together with the National Framework Implementation Working Group. An outline of National Standards for Out-of-home Care. 2011.

8. Murray L, Tarren-Sweeney M, France K. Foster carer perceptions of support and training in the context of high burden of care. Child \& Family Social Work. 2011;16(2):149-58.

9. York $\mathrm{W}$, Jones J. Addressing the mental health needs of looked after children in foster care: the experiences of foster carers. J Psychiatr Ment Health Nurs. 2017;24(2/3):143-53.

10. Blythe SL, Halcomb EJ, Wilkes L, Jackson D. Caring for vulnerable children: Challenges of mothering in the Australian foster care system. Contemporary Nurse: A Journal for the Australian Nursing Profession. 2013;44(1):87-98.

11. Kerns SEU, Pullmann MD, Putnam B, Buher A, Holland S, Berliner L, et al. Child welfare and mental health: Facilitators of and barriers to connecting children and youths in out-of-home care with effective mental health treatment. Children \& Youth Services Review. 2014;46:315-24.

12. Chambers MF, Saunders AM, New BD, Williams CL, Stachurska A. Assessment of children coming into care: processes, pitfalls and partnerships. Clin. 2010;15(4):511-27.

13. Octoman $\mathrm{O}, \mathrm{McLean} \mathrm{S}$. Challenging behaviour in foster care: what supports do foster carers want? Adoption \& Fostering. 2014;38(2):149-58.

14. Sawyer MG, Carbone JA, Searle AK, Robinson P. The mental health and wellbeing of children and adolescents in home-based foster care. Med J Aust. 2007;186(4):181-4.

15. Withington T, Burton J, Lonne B, Eviers A. Carer perspectives of factors affecting placement trajectories of children in out-of-home care. Children and Youth Services Review. 2016;65:42-50.

16. Department of Health and Human Services, Victoria. Victorian handbook for foster carers. Melbourne 2017.

17. Harris PA TR, Thielke R, Payne J, Gonzalez N, G. Conde JG. Research electronic data capture (REDCap) - A metadata-driven methodology and workflow process for providing translational research informatics support. J Biomed Inform. 2009;42(2):377-81.

18. Foster Care Association of Victoria. Foster Carer Snapshot March 2019. Melbourne, Victoria. 2019.

19. Foster Care Association of Victoria. Carer Life Survey. Melbourne, Victoria. 2018.

20. Tarren-Sweeney M. Concordance of mental health impairment and service utilization among children in care. Clin. 2010;15(4):481-95.

21. Knight EK, McDuffie MJ, Gifford K, Zorc C. Health Service Utilization of Children in Delaware Foster Care, 2013-2014. Del Med J. 2016;88(2):46-52.

22. Australian Institute of Family Studies. LSAC Annual Statistical Report 2017, Vol 8. Melbourne: AIFS; 2018. 
23. Melbye ML, Chi DL, Milgrom P, Huebner CE, Grembowski D. Washington state foster care: dental utilization and expenditures. J Public Health Dent. 2014;74(2):93-101.

24. Do, LG and Spencer, AJ. Oral health of Australian children: the National Child Oral Health Study 2012-

14. Adelaide: University of Adelaide Press; 2016.

25. Kaltner M, Rissel K. Health of Australian children in out-of-home care: needs and carer recognition. Journal of Paediatrics \& Child Health. 2011;47(3):122-6.

26. Rubin D, O'Reilly, A., Luan, X., Localio, A.R. The Impact of Placement Stability on Behavioral Well-being for Children in Foster Care. Pediatrics. 2007;119(2):336-44.

27. Victorian Ombudsman. Investigation into the financial support provided to kinship carers. Melbourne, Victoria; 2017.

28. To be supplied after peer review

29. Foster Care Association of Victoria. Victorian Foster Carer Census. Melbourne; 2016. 
Table 1: Survey topics and question types

\begin{tabular}{ll}
\hline Area & Topics \\
\hline Carer experience & Type of carer; duration as a carer; number of children cared for; longest placement \\
\hline Experiences relating to a specific child/ young person & Age bracket of child; number of previous placements; health services attended. \\
in their care (currently or most recently in their care) & Ease of making appointments with health services. \\
\hline Potential barriers to healthcare & Medicare card/number availability \\
& Out-of-pocket expenses and frequency of reimbursement \\
\hline Carer impression of health needs management & Carer opinion on whether child or young person had received a comprehensive \\
& assessment of needs across different health domains \\
\hline Demographics of respondent & Age, sex, postcode, level of education \\
\hline
\end{tabular}

This article is protected by copyright. All rights reserved. 


\begin{tabular}{|c|c|c|c|c|}
\hline & Foster (n, \%) & $\begin{array}{l}\text { Kinship (n, } \\
\text { \%) }\end{array}$ & $\begin{array}{l}\text { Victorian data, } \\
\text { (\%) }\end{array}$ & Total \\
\hline Carer type & $239(82)$ & $51(18)$ & $81 \%$ kinship $^{1}$ & $290(100)$ \\
\hline Gender & & & Not available. & \\
\hline Female & $190(84)$ & $46(98)$ & Two thirds of & $236(87)$ \\
\hline Male & $33(15)$ & $1(2)$ & foster carers care & $34(13)$ \\
\hline Prefer not to say & $2(1)$ & 0 & with a partner. ${ }^{29}$ & $2(1)$ \\
\hline Age & & & $\begin{array}{l}\text { Victorian foster } \\
\text { carers }^{29}\end{array}$ & $\mathrm{n}=272 *$ \\
\hline 18-35 years old & $19(8)$ & $7(15)$ & $11 \%$ & $26(10)$ \\
\hline 36 - 45 years old & $66(29)$ & 9 (19) & $27 \%$ & $127(47)$ \\
\hline $46-65$ years old & $125(56)$ & $26(55)$ & $53 \%$ & $99(36)$ \\
\hline over 65 years old & $12(5)$ & $5(11)$ & $10 \%$ & $17(6)$ \\
\hline Prefer not to say & $3(1)$ & 0 & & $3(1)$ \\
\hline Indigenous status of carer & & & Victorian foster & $\mathrm{n}=268^{*}$ \\
\hline $\begin{array}{l}\text { Aboriginal and/or Torres Strait } \\
\text { Islander }\end{array}$ & $8(4)$ & $4(9)$ & $\begin{array}{l}\text { carers } \\
2.5 \%^{29}\end{array}$ & $12(5)$ \\
\hline Highest level of education of carer & & & & $\mathrm{n}=268^{*}$ \\
\hline Did not finish high school & $22(10)$ & $7(15)$ & N/A & $29(11)$ \\
\hline Year 12 or Certificate III/IV & $47(21)$ & $23(50)$ & N/A & $70(26)$ \\
\hline University & $153(69)$ & $16(35)$ & $43 \%{ }^{29}$ & $169(63)$ \\
\hline Length of time as carer & & & $\begin{array}{l}\text { Victorian foster } \\
\text { carers }^{29}\end{array}$ & $\mathrm{n}=289 * 34$ \\
\hline$<1$ year & $27(11)$ & $7(14)$ & $15 \%$ & $(12)$ \\
\hline $1-5$ years & $101(42)$ & $27(53)$ & $41 \%$ & $128(44)$ \\
\hline $6-10$ years & $42(18)$ & $8(16)$ & $18 \%$ & $50(17)$ \\
\hline$>10$ years & $68(29)$ & $9(18)$ & $26 \%$ & $77(27)$ \\
\hline Age of child for health questions & & & Victorian data $^{1}$ & $\mathrm{n}=290^{*}$ \\
\hline$<12$ months old & $18(8)$ & $1(2)$ & $4 \%$ & $19(7)$ \\
\hline $1-3$ years old & $42(18)$ & $9(18)$ & $1-4$ years: $24 \%$ & $51(18)$ \\
\hline $4-6$ years old & $42(18)$ & $14(28)$ & 5-9 years: $28 \%$ & $56(19)$ \\
\hline $7-12$ years old & $86(36)$ & $17(33)$ & $10-14$ years: $28 \%$ & $103(36)$ \\
\hline $13-17$ years old & $51(21)$ & $10(20)$ & $15-17$ years: $16 \%$ & $61(21)$ \\
\hline
\end{tabular}

Indigenous status of child 


\begin{tabular}{lllll}
\hline $\begin{array}{l}\text { Aboriginal and/or Torres Strait } \\
\text { Islander }\end{array}$ & $61(26)$ & $10(20)$ & $26 \%^{1}$ & $72(25)$ \\
\hline $\begin{array}{l}\text { Number of previous placements of } \\
\text { child }\end{array}$ & & & N/A & $\mathrm{n}=260^{*}$ \\
0 & $43(18)$ & $23(45)$ & & $66(23)$ \\
1 & $48(20)$ & $16(31)$ & & $64(22)$ \\
2 & $26(11)$ & $1(2)$ & & $27(9)$ \\
3 or more & $101(42)$ & $10(20)$ & $111(38)$ \\
Don't know & $21(9)$ & $1(2)$ & & $22(8)$ \\
\hline
\end{tabular}

*Questions were not mandatory, therefore total (n) varies

N/A: Not available

Percentage totals may exceed 100 due to rounding 
Table 3: Proportions engaging with health services and risk ratios

This article is protected by copyright. All rights reserved. 


\begin{tabular}{|c|c|c|c|c|c|c|c|c|c|c|c|c|c|c|}
\hline & \multicolumn{2}{|c|}{ GP } & \multicolumn{2}{|c|}{ Paediatrician } & \multicolumn{2}{|c|}{ Dentist } & \multicolumn{2}{|c|}{ Audiology } & \multicolumn{2}{|c|}{ Optometry } & \multicolumn{2}{|c|}{ Psychology } & \multicolumn{2}{|c|}{ CAMHS } \\
\hline & $\begin{array}{c}\% \\
\text { engaged }\end{array}$ & $\begin{array}{l}\text { Risk ratio } \\
(95 \% \mathrm{Cl})\end{array}$ & $\begin{array}{c}\% \\
\text { engaged }\end{array}$ & $\begin{array}{l}\text { Risk ratio } \\
(95 \% \mathrm{Cl})\end{array}$ & $\begin{array}{c}\% \\
\text { engaged }\end{array}$ & $\begin{array}{l}\text { Risk ratio } \\
(95 \% \mathrm{Cl})\end{array}$ & $\begin{array}{c}\% \\
\text { engaged }\end{array}$ & $\begin{array}{l}\text { Risk ratio } \\
(95 \% \mathrm{Cl})\end{array}$ & $\begin{array}{c}\% \\
\text { engaged }\end{array}$ & $\begin{array}{l}\text { Risk ratio } \\
(95 \% \mathrm{Cl})\end{array}$ & $\begin{array}{c}\% \\
\text { engaged }\end{array}$ & $\begin{array}{l}\text { Risk ratio } \\
(95 \% \mathrm{Cl})\end{array}$ & $\begin{array}{c}\% \\
\text { engaged }\end{array}$ & $\begin{array}{l}\text { Risk ratio } \\
(95 \% \mathrm{Cl})\end{array}$ \\
\hline \multicolumn{15}{|l|}{ Care type } \\
\hline Foster & 89 & 1.00 & 73 & 1.00 & 72 & 1.00 & 55 & 1.00 & 60 & 1.00 & 50 & 1.00 & 20 & 1.00 \\
\hline Kinship & 92 & $\begin{array}{c}1.03(0.94- \\
1.12)\end{array}$ & 71 & $\begin{array}{c}.98(0.80- \\
1.20)\end{array}$ & 90. & $\begin{array}{c}1.25(1.11- \\
1.42)^{* *}\end{array}$ & 52 & $\begin{array}{c}0.95(0.70 \\
-1.29)\end{array}$ & 68 & $\begin{array}{c}1.14(0.91- \\
1.43)\end{array}$ & 57 & $\begin{array}{c}1.15(0.87 \\
-1.52)\end{array}$ & 26 & $\begin{array}{c}1.26(0.72- \\
2.19)\end{array}$ \\
\hline \multicolumn{15}{|l|}{ Location } \\
\hline Regional & 95 & 1.00 & 81 & 1.00 & 83 & 1.00 & 60 & 1.00 & 69 & 1.00 & 50 & 1.00 & 22 & 1.00 \\
\hline Metropolitan & 89 & $\begin{array}{c}0.94(0.87- \\
1.01) \\
\end{array}$ & 68 & $\begin{array}{c}0.84(0.72- \\
0.98)^{*} \\
\end{array}$ & 70 & $\begin{array}{c}0.84(0.74 \\
-0.97)^{*}\end{array}$ & 54 & $\begin{array}{c}0.90(0.72 \\
-1.13) \\
\end{array}$ & 56 & $\begin{array}{c}0.81(0.67- \\
0.99)^{*} \\
\end{array}$ & 51 & $\begin{array}{c}1.00(0.78 \\
-1.29) \\
\end{array}$ & 22 & $\begin{array}{c}1.01(0.62- \\
1.64) \\
\end{array}$ \\
\hline \multicolumn{15}{|l|}{ SEIFA quintile } \\
\hline 1 & 86 & 1.00 & 70 & 1.00 & 75 & 1.00 & 50 & 1.00 & 57 & 1.00 & 41 & 1.00 & 19 & 1.00 \\
\hline 2 & 94 & $\begin{array}{c}1.10(0.93- \\
1.29)\end{array}$ & 83 & $\begin{array}{c}1.18(0.89- \\
1.56)\end{array}$ & 84 & $\begin{array}{c}1.13(0.88 \\
-1.44)\end{array}$ & 63 & $\begin{array}{c}1.27(0.80 \\
-2.01)\end{array}$ & 67 & $\begin{array}{c}1.17(0.79- \\
1.72)\end{array}$ & 55 & $\begin{array}{c}1.32(0.79 \\
-2.20)\end{array}$ & 23 & $\begin{array}{c}1.26(0.48- \\
3.29)\end{array}$ \\
\hline 3 & 90 & $\begin{array}{c}1.05(0.89- \\
1.24)\end{array}$ & 70 & $\begin{array}{c}1.00(0.75- \\
1.33)\end{array}$ & 76 & $\begin{array}{c}1.02(0.79 \\
-1.30)\end{array}$ & 51 & $\begin{array}{c}1.01(0.64 \\
-1.61)\end{array}$ & 65 & $\begin{array}{c}1.14(0.80- \\
1.64)\end{array}$ & 49 & $\begin{array}{c}1.19(0.73 \\
-1.95)\end{array}$ & 19 & $\begin{array}{c}1.04(0.41- \\
2.60)\end{array}$ \\
\hline 4 & 92 & $\begin{array}{c}1.08(0.91- \\
1.27)\end{array}$ & 72 & $\begin{array}{c}1.02(0.76- \\
1.36)\end{array}$ & 74 & $\begin{array}{c}0.98(0.76 \\
-1.27)\end{array}$ & 56 & $\begin{array}{c}1.11(0.70 \\
-1.76)\end{array}$ & 63 & $\begin{array}{c}1.09(0.75- \\
1.59)\end{array}$ & 54 & $\begin{array}{c}1.30(0.80 \\
-2.12)\end{array}$ & 25 & $\begin{array}{c}1.35(0.55- \\
3.31)\end{array}$ \\
\hline 5 & 91 & $\begin{array}{c}1.06(0.89- \\
1.27) \\
\end{array}$ & 65 & $\begin{array}{c}0.93(0.67- \\
1.28) \\
\end{array}$ & 69 & $\begin{array}{c}0.92(0.69 \\
-1.23)\end{array}$ & 59 & $\begin{array}{c}1.18(0.74 \\
-1.89) \\
\end{array}$ & 51 & $\begin{array}{c}0.90(0.58- \\
1.38) \\
\end{array}$ & 54 & $\begin{array}{c}1.29(0.77 \\
-2.16) \\
\end{array}$ & 26 & $\begin{array}{c}1.41(0.55- \\
3.62)\end{array}$ \\
\hline \multicolumn{15}{|l|}{ Age of child } \\
\hline $\begin{array}{l}\text { Less than } 12 \\
\text { months }\end{array}$ & 89 & 1.00 & 83 & 1.00 & 7 & $\begin{array}{c}0.09(0.01 \\
-0.62)^{*}\end{array}$ & 60 & 1.00 & 14 & $\begin{array}{c}0.25(0.07- \\
0.93)^{*}\end{array}$ & 17 & 1.00 & 0 & - \\
\hline $1-3$ years old & 96 & $\begin{array}{c}1.08(0.91- \\
1.28)\end{array}$ & 87 & $\begin{array}{c}1.04(0.82- \\
1.32)\end{array}$ & 58 & $\begin{array}{c}0.76(0.57- \\
1.00)\end{array}$ & 60 & $\begin{array}{c}0.99(0.62 \\
-1.60)\end{array}$ & 39 & $\begin{array}{c}0.69(0.45- \\
1.07)\end{array}$ & 17 & $\begin{array}{c}1.04(0.31 \\
-3.50)\end{array}$ & 9 & $\begin{array}{c}1.11(0.29- \\
4.18)\end{array}$ \\
\hline $4-6$ years old & 88 & $\begin{array}{c}0.98(0.81- \\
1.19)\end{array}$ & 68 & $\begin{array}{c}0.81(0.62- \\
1.07)\end{array}$ & 77 & 1.00 & 54 & $\begin{array}{c}0.90(0.55 \\
-1.45)\end{array}$ & 56 & 1.00 & 40 & $\begin{array}{c}2.38(0.80 \\
-7.04)\end{array}$ & 8 & 1.00 \\
\hline $\begin{array}{l}7-12 \text { years } \\
\text { old }\end{array}$ & 87 & $\begin{array}{c}0.98(0.82- \\
1.17)\end{array}$ & 74 & $\begin{array}{c}0.88(0.70- \\
1.12)\end{array}$ & 85 & $\begin{array}{c}1.10(0.93 \\
-1.30)\end{array}$ & 56 & $\begin{array}{c}0.94(0.60 \\
-1.47)\end{array}$ & 72 & $\begin{array}{c}1.28(0.98- \\
1.67)\end{array}$ & 65 & $\begin{array}{c}3.92(1.38 \\
-11.1)^{*}\end{array}$ & 25 & $\begin{array}{c}3.15(1.15- \\
8.62)^{*}\end{array}$ \\
\hline $\begin{array}{l}13-17 \text { years } \\
\text { old }\end{array}$ & 92 & $\begin{array}{c}1.03(0.86- \\
1.23)\end{array}$ & 59 & $\begin{array}{c}0.71(0.52- \\
0.96)^{*}\end{array}$ & 87 & $\begin{array}{c}1.13(0.95 \\
-1.34)\end{array}$ & 45 & $\begin{array}{c}0.75(0.45 \\
-1.25)\end{array}$ & 76 & $\begin{array}{c}1.35(1.02- \\
1.77)^{*}\end{array}$ & 75 & $\begin{array}{l}4.47(1.58 \\
-12.7)^{* *}\end{array}$ & 44 & $\begin{array}{c}5.59(2.09- \\
14.9)^{* *}\end{array}$ \\
\hline \multicolumn{15}{|l|}{ Education level carer } \\
\hline Year 11 or below & 96 & 1.00 & 79 & 1.00 & 75 & 1.00 & 57 & 1.00 & 74 & 1.00 & 50 & 1.00 & 23 & 1.00 \\
\hline $\begin{array}{l}\text { Year } 12 \text { or Cert } \\
\text { III/IV }\end{array}$ & 94 & $\begin{array}{c}0.98(0.89- \\
1.07)\end{array}$ & 78 & $\begin{array}{c}0.99(0.77- \\
1.26)\end{array}$ & 87 & $\begin{array}{c}1.16(0.92 \\
-1.46)\end{array}$ & 63 & $\begin{array}{c}1.12(0.75 \\
-1.67)\end{array}$ & 74 & $\begin{array}{c}1(0.76- \\
1.32)\end{array}$ & 48 & $\begin{array}{c}0.96(0.60 \\
-1.53)\end{array}$ & 24 & $\begin{array}{c}1.05(0.44- \\
2.54)\end{array}$ \\
\hline
\end{tabular}




\begin{tabular}{|c|c|c|c|c|c|c|c|c|c|c|c|c|c|c|}
\hline University & 89 & $\begin{array}{c}0.92(0.84- \\
1.01)\end{array}$ & 69 & $\begin{array}{c}0.87(0.69- \\
1.10)\end{array}$ & 71 & $\begin{array}{l}0.95(0.75 \\
-1.20)\end{array}$ & 52 & $\begin{array}{l}0.92(0.62 \\
-1.36)\end{array}$ & 54 & $\begin{array}{c}0.74(0.56- \\
0.98)^{*}\end{array}$ & 53 & $\begin{array}{c}1.06(0.69 \\
-1.62)\end{array}$ & 22 & $\begin{array}{c}0.96(0.42- \\
2.18)\end{array}$ \\
\hline
\end{tabular}




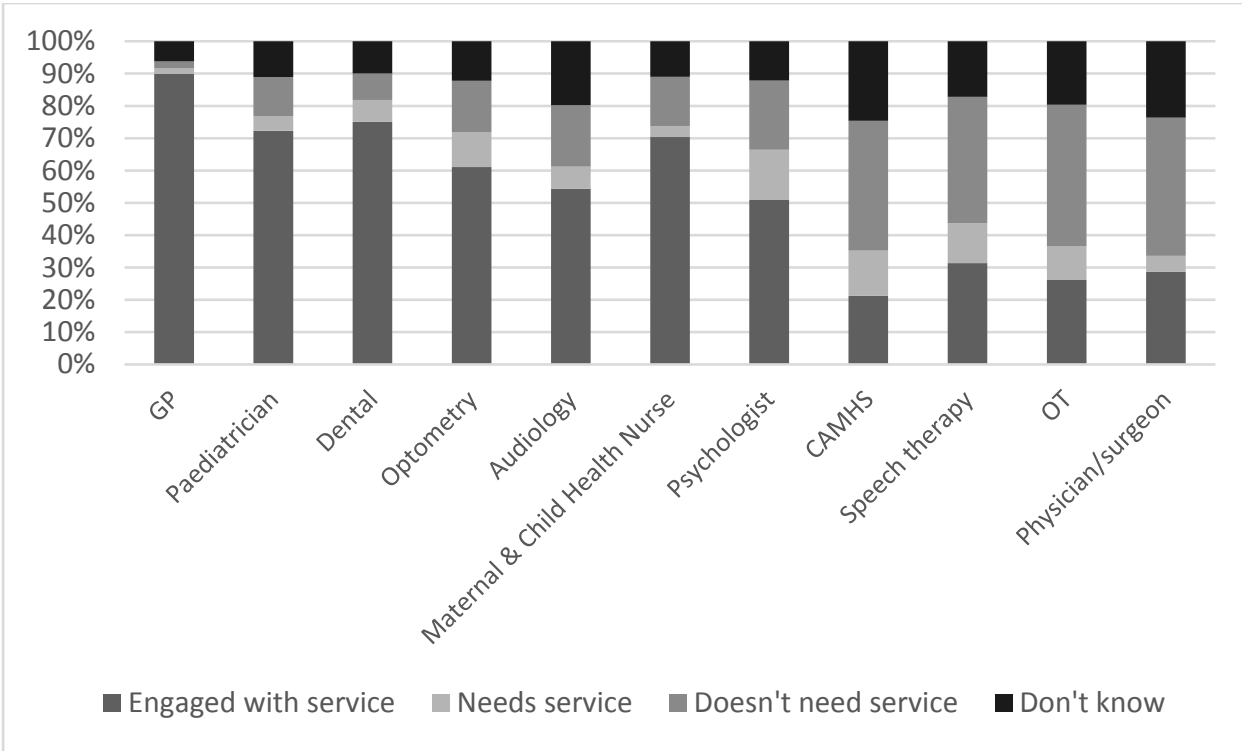

Figure 1: Proportion of children/young people engaged with health services

This article is protected by copyright. All rights reserved. 


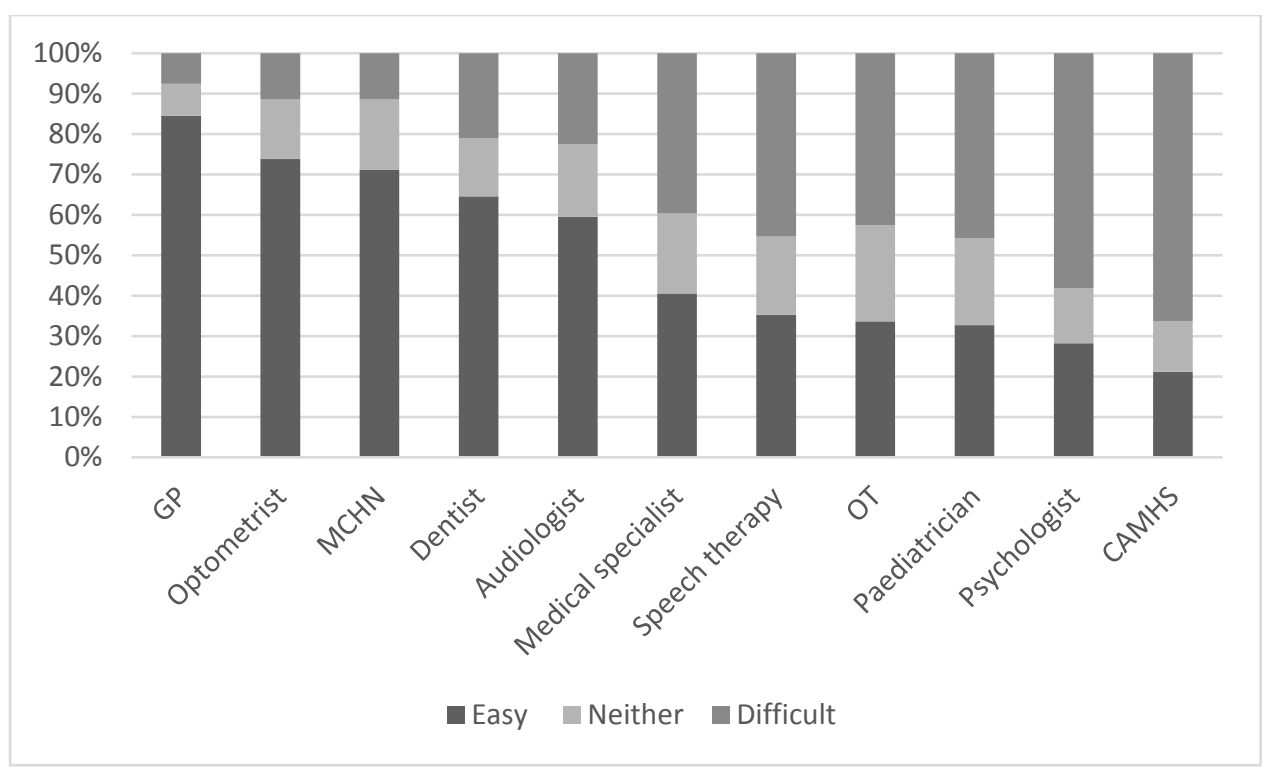

Figure 2: Ease of making appointments at health services

This article is protected by copyright. All rights reserved. 


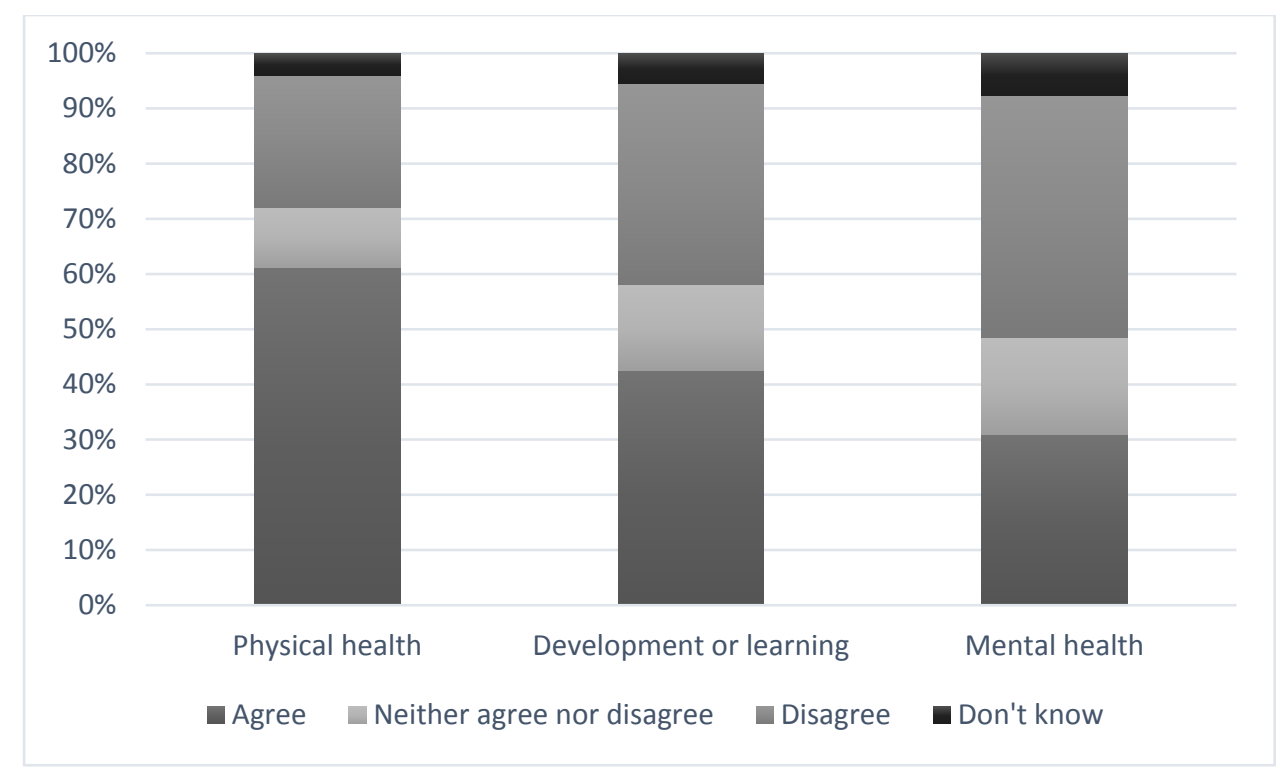

Figure 3 Proportion of carers believing child has had good assessment of health needs

This article is protected by copyright. All rights reserved. 


\section{FOSTER AND KINSHIP CARER SURVEY: ACCESSING HEALTH SERVICES FOR CHILDREN IN OUT-OF-HOME CARE}

Type of manuscript: Original article

Karen McLean ${ }^{1,2,3}$, Harriet Hiscock ${ }^{2,3,4,5}$, Dorothy Scott $^{6}$, Sharon Goldfeld ${ }^{1,2,3}$

\section{Addresses of institutions}

1. Policy and Equity, Murdoch Children’s Research Institute, Parkville, Victoria, Australia;

2. Centre for Community Child Health, Royal Children’s Hospital, Parkville, Victoria, Australia;

3. Department of Paediatrics, University of Melbourne, Parkville, Victoria, Australia.

4. Health Services, Murdoch Children’s Research Institute, Parkville, Victoria, Australia

5. Health Services Research Unit, Royal Children’s Hospital, Parkville, Victoria, Australia

6. Department of Social Work, Health Sciences, University of Melbourne

\section{Full postal, email addresses and phone number of corresponding author}

Corresponding author:

Dr Karen McLean

Address: Centre for Community Child Health, Level 2 East, Royal Children’s Hospital, 50 Flemington Road, Parkville, VIC 3052, Australia.

Email: karen.mclean@rch.org.au

Phone: +61 393456504

\section{Acknowledgements}

KMcL led the research project and the writing of the paper. All authors contributed to planning the analysis, writing the paper and reviewing drafts.

Thanks to the Foster Care Association of Victoria for co-design and pilot-testing of the survey and for distributing the survey to members; thanks to Kinship Carers Victoria for 
distributing the survey to their members, and to the foster care agencies who encouraged carers to complete the survey.

This research is supported the Victorian Government's Operational Infrastructure Support Program. KM is supported by an Australian Government Research Training Program Scholarship PhD scholarship and Murdoch Children's Research Institute scholarship. SG is supported by Australian National Health and Medical Research Council (NHMRC) Career Development Fellowship 1082922. HH is supported by Australian National Health and Medical Research Council (NHMRC) Career Development Fellowship 113622.

No author has a conflict of interest. 


\section{University Library}

\section{- M M I N E R VA A gateway to Melbourne's research publications}

Minerva Access is the Institutional Repository of The University of Melbourne

Author/s:

McLean, K;Hiscock, H;Scott, D;Goldfeld, S

Title:

Foster and kinship carer survey: Accessing health services for children in out-of-home care

Date:

2020-09-19

Citation:

McLean, K., Hiscock, H., Scott, D. \& Goldfeld, S. (2020). Foster and kinship carer survey: Accessing health services for children in out-of-home care. JOURNAL OF PAEDIATRICS AND CHILD HEALTH, 57 (1), pp.132-139. https://doi.org/10.1111/jpc.15157.

Persistent Link:

http://hdl.handle.net/11343/276325 